\title{
Los viajes de los intelectuales latinoamericanos a Europa Oriental 1947-1956: organización, circuitos de contacto y reflexiones
}

\begin{abstract}
Palabras clave: intelectuales, América Latina, relaciones culturales, Guerra Fría, comunismo, Consejo Mundial de la Paz, Jorge Amado, Pablo Neruda, Nicolás Guillén
\end{abstract}

DOI: $10.4312 /$ ars.11.2.331-347

\section{Introducción}

La Guerra Fría influyó significativamente en América Latina, algo que fue visible también en la escena cultural local. Para los intelectuales y artistas de izquierda el conflicto bipolar no significó solamente la persecución por parte de regímenes autoritarios, sino que también contribuyó significativamente a que el mundo empezara a «descubrir» sus trabajos. Las obras de los autores latinoamericanos se empezaron a traducir a muchas lenguas extranjeras, ganaban premios internacionales, sus autores estaban invitados a participar en conferencias internacionales y todo ello en una cantidad sin precedentes.

La extensión del radio de acción de los intelectuales latinoamericanos fuera del continente estuvo estrechamente relacionada con el hecho de que la región se convirtió por primera vez en una parte decisiva de la política internacional. Un importante instrumento usado por ambos bloques en la confrontación mutua fue la propagación cultural. Latinoamérica representa un ejemplo ilustrativo de dicha confrontación (Joseph, 2004, 67-92). El miedo de la amenaza comunista y su penetración en el hemisferio occidental llevó a Washington a iniciar una serie de operaciones psicológicas y programas culturales (Osgood, 2006, 113-114). Al mismo tiempo, desde la segunda mitad de los años cincuenta, podemos ver una creciente propagación cultural de los países comunistas: visitas de varios conjuntos artísticos, radiodifusión, distribución de revistas, literatura, películas o la oferta de becas para estudiantes (Rupprecht, 2015, 22-72).

Es evidente que la distancia poco a poco se convirtió en un concepto relativo, ante todo gracias al desarrollo tecnológico, y este fenómeno ayudó a promover la 
«internacionalización» de los artistas del Tercer Mundo de una manera fundamental. Sin embargo, hay que tener en cuenta el hecho de que los Estados Unidos, la Unión Soviética y China difícilmente habrían impulsado la creación de organizaciones internacionales de artistas, habrían financiado las visitas de los escritores latinoamericanos en tal medida, ni hubieran promovido las publicaciones de sus obras. Dichas políticas fueron motivadas por un esfuerzo de reforzar su influencia en el importante campo de la batalla ideológica que en aquella época representó América Latina, y para así contribuir a la derrota final del enemigo.

La derecha conservadora veía en Europa Oriental un mundo atrasado de bárbaros salvajes, mientras que los comunistas la elogiaban como un paraíso utópico. Cualquiera que fuera el mundo detrás del Telón de Acero, símbolo de miedo o esperanza, la mayoría de estas informaciones destinadas al público latinoamericano aparecían muy distorsionadas y eran manipuladoras. La descripción de la vida en los países comunistas fue parte de la batalla ideológica y por eso una mirada equilibrada era algo prácticamente inexistente. La Europa Oriental comunista provocaba así una serie de emociones contradictorias. En todos casos, eran pocos aquellos que no se interesaban por una región que luchaba contra los Estados Unidos, que deseaban lograr la hegemonía mundial.

Mientras la política cultural norteamericana en Latinoamérica se ha analizado desde casi todos los puntos de vista, la propaganda cultural de la Unión soviética ha sido, con pocas excepciones (Riza, Quirk, 1972), pasada por alto hasta hace poco. La situación ha cambiado principalmente gracias al cambio en la mirada global a la historia. La «Global history» representa una tendencia historiográfica que reacciona al proceso de globalización, a la importancia decreciente de los estados nacionales, así como a una crítica poscolonial del eurocentrismo. Así pues, la historia interpretada de esta manera dirige su atención a los fenómenos históricos transnacionales y transculturales (Iggers, Wang, Mukherjee, 2008; Middel, Hadler, 2007, 293-306). Por lo tanto, la penetración de la cultura soviética en Latinoamérica, así como la percepción latinoamericana del comunismo como uno de los fenómenos transnacionales más significativos del siglo XX, están en el centro de atención de los investigadores (Rupprecht, 2015; Alburquerque, 2011; Pedemonte, 2010; Galvan, Zourek, 2016; Galvan, 2017).

Un capítulo aparte en la investigación de los problemas mencionados lo representa la participación de los intelectuales latinoamericanos en la Guerra Fría. Este tema, el cual es el objeto de este estudio, es tradicionalmente de gran interés entre los investigadores y lo encontramos en un gran número de estudios que analizan este asunto tanto desde un punto de vista nacional (Camp, 1988; Pecaut, 1990; Terán 
1991; Sigal 1991; Rojas 2006), como continental (Uricoechea, 1969; Mudrovcic, 1997; Franco, 2002; Gilman, 2003; Monsiváis, 2007).

Este estudio presta atención a un apecto poco conocido. Nos referiremos a los viajes de los intelectuales latinoamericanos a los países comunistas de Europa del Este y a los testimonios escritos en los que están documentadas las experiencias de estos viajes. Poco después de la Revolución Rusa, muchos intelectuales latinoamericanos anhelaron ver el país donde "el mañana ya es ayer» con sus propios ojos y manifestar así su solidaridad con el régimen comunista. El aumento más significativo del número de estos viajes tuvo lugar después de la Segunda Guerra Mundial.

El destino principal siguió siendo la Unión Soviética, sin embargo, aparecen también otros países socialistas, como Checoslovaquia. Este país representó un puente imaginario entre la Unión Soviética y Europa del Este y funcionó como «una puerta» al mundo detrás del Telón de Acero. La mayoría de los visitantes llegaron a Moscú desde el aeropuerto de Praga. Por razones geográficas y logísticas también hubo una gran cantidad de organizaciones internacionales (Zourek, 2014, 26-27) y muchos congresos tuvieron lugar allí. Checoslovaquia fue también un centro importante de emigración política desde Grecia, Italia, España y Yugoslavia (Bárta, 2011, 15-22). Hasta el final de los años 60, por poner un ejemplo, el Partido Comunista de España tuvo su sede en Praga (Nálevka, 2005, 77-95).

Por las razones mencionadas anteriormente, Annie Kriegel, historiadora francesa, dio a la metrópoli checoslovaca el nombre de "la Ginebra comunista» (Bartošek, 1996). Las visitas a otros países de Europa del Este fueron de carácter excepcional, y la principal motivación era, en la mayoría de casos, la participación en un congreso o festival, y por eso hay muchos menos testimonios de estas visitas. Yugoslavia, por su parte, quedó completamente fuera del itinerario de los intelectuales latinoamericanos, ya que en el año 1948 fue expulsada de la Kominform ${ }^{1}$ debido a las disputas personales entre Tito y Stalin.

Algunos intelectuales viajaron a Europa del Este para trabajar allí y otros llegaron por su cuenta o bien obtuvieron asilo político. Esto dio lugar a decenas de testimonios, entre cuyos autores podemos encontrar también a algunas de las voces más destacadas de la literatura mundial. Estas obras, en muchos casos olvidadas, reflejan extraordinariamente los cambios en la percepción de la realidad de Europa del Este. Entre ellas se pueden encontrar panfletos panegíricos de los años cuarenta y cincuenta, marcados por el estalinismo (Amado, 1953), reportajes politizados, pero

1 La organización era uno de los instrumentos claves de la política internacional de la URSS que aseguraba el intercambio de información y experiencias entre los partidos comunistas. La sucesora de la Komintern funcionó en el período de 1947-1956. 
ya más objetivos (García Márquez, 2015), libros de carácter informativo y etnográfico (Malbec, 1963; Torres, 1962), reportajes que engrandecían la calidad de la escena cultural (Galeano, 2011) y también una dura crítíca del realismo socialista, con mayor frecuencia desde la segunda mitad de los años sesenta (Dalton, 1969), y que está presente hasta la caída de los regímenes comunistas a finales de los años ochenta (Bergstein, 1996). A la vez hay que mencionar las memorias que reflexionan sobre los cambios radicales de percepción (Amado, 1992; Gattai, 1991; Delgado, 2007).

Este estudio trata en más detalle las obras de los años 1947-1956, es decir, de la primera década de la Guerra Fría. El prestigio de la Unión Soviética, que contribuyó significativamente a la derrota del fascismo, así como la simpatía de los intelectuales izquierdistas hacia la Unión Soviética alcanzan su máximo esplendor. No es casualidad que el mayor número de testimonios de los intelectuales latinoamericanos de sus viajes por Europa Oriental provenga de este período. El XX Congreso del Partido Comunista de la URSS celebrado en febrero de 1956, donde Nikita Khrushchev habló abiertamente sobre los crímenes del estalinismo, y la sangrienta invasión en Hungría, que tuvo lugar en otoño del mismo año, simbolizan el fin de esta etapa. La creencia en la utopía fue reemplazada por la desilusión, muchos personajes de la época rompieron con las ideas del movimiento comunista y en el mapa del mundo empezaron a aparecer nuevos destinos de «turismo revolucionario». Primero China y después ante todo Cuba se convirtieron en nuevos símbolos de la justicia social y la creencia de la existencia de un mundo mejor.

\section{Los intelectuales como arma de la propaganda comunista}

El historiador Pascal Ory definió el período de los años 1947-1956 como «la Guerra Fría de los intelectuales comunistas» (Sirinelli, Ory, 2007, 189). La puerta al comunismo para centenares de ellos fue el movimiento antifascista. Desde el punto de vista de Latinoamérica hay que destacar la influencia de la Guerra Civil en España, cuyas repercusiones fueron sin duda, por la cercanía cultural, comparables con ambas guerras mundiales. Para muchos intelectuales los recuerdos de los recientes y trágicos acontecimientos fomentaban la responsabilidad y el esfuerzo en defender valores culturales, que según ellos se veían amenazados por la llegada del nuevo «imperialismo fascista», identificado con los EE.UU.

El libro de Jorge Amado O Mundo da Paz (El Mundo de la Paz, 1951) es todo un símbolo de esta época, escrito durante los primeros meses de su exilio en Checoslovaquia, donde vivía con su familia entre los años 1950-1952. En esta obra dedicada a Stalin el autor define a los intelectuales como unos soldados en una batalla 
en la que se decide el destino del hombre. Poco después, Amado se distanció de este texto lleno de informaciones incorrectas y engañosas y prohibió su publicación. Pese a todo, este libro es un testimonio notable de la época y su importancia se debe también al hecho de que el autor presta su atención a todos los países del Bloque de Este, visitados entre 1948-1950.

Uno de los primeros autores latinoamericanos entre aquellos que tras la Segunda Guerra Mundial emprendieron el viaje a la Meca comunista, fue el escritor y periodista argentino, Alfredo Varela, conocido ante todo por su novela El Río Oscuro. Varela residió en la Unión Soviética desde diciembre de 1948 hasta marzo de 1949 y fue tan entusiasta que al volver a Argentina escribió una elegía de más de cuatrocientas páginas con el título de Un periodista argentino en la Unión Soviética (1950).

Nicolás Guillén, aclamado poeta cubano, fue uno de los defensores más leales de la Unión Soviética. Exiliado en París, Guillén visitó Europa del Este por primera vez en el año 1949 y desde entonces más de diez veces. Sus experiencias e impresiones están descritas en varios textos en prosa dedicados a la URSS (1982, 296-303), Checoslovaquia (1982, 290-296), Rumanía (16., 23., 30. 12. 1951), Hungría (5. 6. 1951) y Bulgaria (29. 5. 1951), donde además escribió La pequeña balada de Plovdiv. En torno a estos versos amorosos se difundió una leyenda acerca del poema, la cual trataba de un testimonio de la aventura entre Guillén y una actriz búlgara. Sin embargo, en realidad, fue una historia completamente inventada (Santana, 1989, 259).

Otro gran poeta, Pablo Neruda, no dejó ningún testimonio escrito, sin embargo, su relación con Europa del Este se refleja en muchos de sus poemas. El más grande poeta del siglo XX en cualquier idioma, como le llamó su amigo, Gabriel García Márquez, visitó por primera vez Europa del Este en 1949, el mismo año en que abandonó su Chile natal en secreto. Su colección de poemas, Las Uvas y el Viento (1954) contiene poemas dedicados a la Unión Soviética, Checoslovaquia y Polonia. A esta habría que unir Canto General, colección en la que el compromiso se hace más evidente y la poesía se convierte en un medio para explicitarlo (Pedemonte, 2015, 160). Neruda no fue el único poeta cuyos poemas están dedicados a los países de Europa del Este, debemos nombrar también por ejemplo a Raúl González Tunón (1954, 128-129, 134-136) y Efraín Huerta $(1956,3)$.

En cuanto a los libros de viajes que describen la atmósfera del principio de los años cincuenta, son dignos de mención los siguientes cuatro autores. El escritor y pedagogo uruguayo Jesualdo Sosa en su libro Mi viaje a la URSS (1952) describe sus experiencias después de las visitas a la Unión Soviética y Checoslovaquia realizadas en 1951; fue, asimismo, autor de muchos libros de pedagogía y presidente de la Sociedad de Amistad Soviético-Uruguaya. 
En 1952 el escritor Graciliano Ramos se encontraba entre los miembros de la numerosa delegación brasileña. Su obra Viagem (1954), publicada póstumamente, trata de las visitas a la Unión Soviética y Checoslovaquia; difiere de otros textos contemporáneos por su tono más crítico, aunque Ramos también prodiga elogios hacia el líder soviético. El libro es interesante además por su estilo literario. Se basa en el contraste entre la crítica y el elogio, la sinceridad cruda y la ironía, sin verse afectado por el realismo soviético, rasgo típico de la estética comunista en aquella época.

Un año después, un compatriota de Jesualdo Sosa, Alfredo Gravina, visitó los mismos países, y publicó sus impresiones en el libro de viajes Crónica de un viaje a la URSS y Checoslovaquia (1955). El autor conocido, ante todo por la novela Fronteras al viento, formó parte de una delegación que recorrió diversos puntos de estos países, por ejemplo, Uzbekistán o ciudades eslovacas.

Luis Suárez, por su parte, fue español de origen, pero emigró a México en 1939. En 1953 participó en el Festival Mundial de la Juventud y los Estudiantes en Bucarest y las impresiones de su estancia en Rumanía, de un mes completo, junto a las más cortas en Polonia y Checoslovaquia las describió en su libro Otro Mundo. Viaje por Checoslovaquia, Rumania y Polonia (1954).

Todos los autores mencionados anteriormente fueron miembros de partidos comunistas y viajaron a Europa del Este con una invitación oficial. Otro aspecto que tienen en común es su participación en el Consejo Mundial de la Paz. Esta organización fundada en 1948 en el Congreso de Breslavia se veía como un órgano internacional independiente, pero sus vínculos con el movimiento comunista internacional eran evidentes. Aproximadamente el $90 \%$ de los recursos financieros de la organización provenían de la Unión Soviética (Alburquerque, 2011, 69).

Moscú, preocupada por el retraso en la carrera armamentística y por su incapacidad de desarrollar armas nucleares, logró hacer una ventaja de este defecto. El Consejo Mundial de la Paz fue el portador del discurso soviético, apercibiendo de las consecuencias desastrosas de guerra y el uso de armas nucleares. Además, gracias a la participación de personas destacadas de todo el mundo, la organización se convirtió en la actividad más exitosa de Moscú en el campo de la propaganda cultural durante la Guerra Fría². Su símbolo, la Paloma de la Paz de Picasso, fue reproducida en millones de folletos distribuidos por todo el mundo.

2 Entre los miembros del Consejo Mundial de la Paz hubo personajes como Pablo Picasso, Louis Aragón, Frederic e Irene Joliot-Curie, Henry Matisse, Rafael Alberti, Alberto Moravia, Luis Buñuel, Dmitri Shostakóvich, Illia Ehrenburg, Nazim Hikmet o György Lukács. De los personajes de Latinoamérica podemos nombrar también a los muralistas mexicanos Diego Rivera y David Alfar Siqueiros, su compatriota y ex-presidente Lázaro Cárdenas o Gabriela Mistral, chilena galardonada con el Premio Nobel. Otros, como Juan Marinello de Cuba, Jorge Zalamea de Colombia y María Rosa Oliver de Argentina ocuparon posiciones altas en la organización. 
El período anterior a 1956 representa el momento de máxima actividad del Consejo Mundial de la Paz, sobre todo durante la Guerra de Corea (1950-1953). Gracias a esta organización, a fines de los años cuarenta, los intelectuales latinoamericanos empezaron a viajar más a Europa del Este para participar en los congresos, conferencias

y festivales. Así, viajar se convirtió en una parte importante de la vida de estos artistas comprometidos políticamente.

\section{Los intelectuales como objeto de la propaganda comunista}

Como se menciona en otros párrafos, los viajes emprendidos en esta época tenían un carácter oficial. Esto significaba que, entre otras cosas, la llegada de visitantes procedentes del extranjero era controlada con atención y el itinerario se planeaba cuidadosamente con respecto a su perfil. Ese fue el papel de la VOKS (Sociedad de toda la Unión Soviética para las Relaciones Culturales con los Países Extranjeros). Esta institución, que organizaba viajes y conferencias y a la vez atendía a los visitantes desde afuera, fue establecida en 1925 por el gobierno soviético para centralizar y controlar mejor el esfuerzo por crear y transmitir una imagen positiva del país hacia el extranjero. La VOKS disponía de una red amplia y tenía representantes también en otros países socialistas (Fayet, 2003, 416-419).

Los visitantes se alojaban en hoteles de lujo, cuidados por guías con perfecto conocimiento de lenguas extranjeras. A los guías se les ordenaba a evitar delicados temas políticos y contrarios a los éxitos del régimen comunista. Así, en los itinerarios se incluían zonas remotas como el Cáucaso, Uzbekistán o Siberia, donde los visitantes podían ver la altruista ayuda rusa para el desarrollo de regiones atrasadas. En cuanto a los visitantes-escritores, el mayor énfasis se ponía en la cultura. Los itineriarios incluían visitas a escuelas, universidades, librerías, teatros, museos o entrevistas con los personajes de la vida cultural, pero no según el estilo de Pueblo Potemkin. Se trataba de verdaderos logros de la cultura, por los que los países de Europa del Este sin duda cautivaron la atención de los visitantes. Los latinoamericanos se veían realmente asombrados tanto por la infraestructura cultural como por la sabiduría de los ciudadanos medios, tomando en cuenta que muchos de sus compatriotas eran iletrados. A menudo se organizaban cenas festivas, cuya parte esencial era el alcohol. La regla más importante era que el visitante siempre estuviera en el centro de atención y que tuviera asistencia completa. No puede sorprender que después de un par de días esta vigilancia resultara molesta. Como recordó Graciliano Ramos: «Los bramantes invisibles nos amarraban piernas y brazos, y las amabilidades excesivas me comenzaban a pesar; aceptarlas me parecía a veces una obligación penosa» (Ramos, 1954, 70). 
Otro instrumento típico de la propaganda comunista dirigida a los escritores extranjeros era la publicación de sus obras. En los países socialistas se trataba de tiradas de decenas de miles de ejemplares, mucho más que en sus países natales. Esta estrategia tenía, sin duda, un efecto beneficioso sobre el ego de estos escritores, con solo una pega, ya que se les pagaba en monedas no convertibles, lo que significaba que podían gastar sus honorarios solamente en ciertos países, una estrategia por parte de los comunistas que obligaba a los autores a llevar a cabo más visitas. Gracias a esta política en la primera mitad de los años cincuenta la producción literaria de Latinoamérica en los países del Bloque de Este estaba representada solo por escritores y autores comunistas. La situación cambió en la segunda mitad, cuando se prefirió centrarse en los autores progresistas, cuyo apoyo no era evidente y había que esforzarse mucho más por él.

El Consejo Mundial de la Paz otorgó a prestigiosos intelectuales extranjeros un premio nacional por promover la paz entre las naciones, que hasta 1956 llevó el nombre de Stalin y después de su predecesor Lenin. Entre los agraciados con este premio soviético, equivalente al Premio Nobel de la Paz, podemos encontrar también representantes de Latinoamérica (Schidlowsky, 2008, 808) ${ }^{3}$. Los intelectuales premiados se hicieron embajadores informales del movimiento comunista internacional y podían encontrarse con los líderes políticos de países remotos. Por ejemplo, María Rosa Oliver conoció a Mao Zedong en China, Jorge Amado a Enver Hoxha en Albania y Pablo Neruda a Jawaharlal Nehru en India (Albuquerque, 2011, 46).

\section{Los circuitos de contacto}

El Consejo Mundial de La Paz era muy importante para establecer contactos entre los intelectuales latinoamericanos con sus compañeros de Europa. Además, no era nada excepcional que los intelectuales latinoamericanos se encontraran por primera vez en Europa Oriental. Muchos de estos encuentros no habían sido planeados y se realizaron gracias a la cuidadosa organización de los itinerarios de estos viajes. Los mismos hoteles, rutas y guías fomentaban estos encuentros que son frecuentemente mencionados en muchos libros de viajes.

En agosto de 1951 tuvo lugar una reunión extraordinaria, cuando después del Festival Mundial de la Juventud y Estudiantes que tuvo lugar en Berlín, Nicolás

3 Heriberto Jara Corona (1950), Jorge Amado (1951), Eliza Branco (1952), Pablo Neruda (1953), Baldomero Sanin Cano (1954), Nicolás Guillén (1954), Lázaro Cárdenas (1955), María Rosa Oliver (1957), Fidel Castro (1961), Olga Poblete de Espinosa (1962), Oscar Niemeyer (1963), Miguel Ángel Asturias (1965), David Alfaro Siqueiros (1966), Jorge Zalamea (1967), Alfredo Varela (1970-71), Salvador Allende (1972), Enrique Pastorino (1972), Luis Corvalán (1973-74), Hortensia Bussi de Allende (1975-76), Vilma Espín Guillois (1977-78), Miguel Otero Silva (1979-80), Líber Seregni (1980-82), Luis Vidales (1983-84), Miguel d’Escoto (1985-86). 
Guillén, Pablo Neruda, Raúl González Tuñón y Alfredo Varela llegaron a Praga, poco después del nacimiento de la hija de Jorge Amado, Paloma, y decidieron visitar a su esposa, Zelia Gattai, en el hospital. Las enfermeras casi se desmayaron al ver la cama envuelta en humo de cigarrillos y rodeada por hombres y mujeres y los distinguidos invitados tuvieron que abandonar el edificio (Gattai, 1991, 155).

Jesualdo Sosa llamó a uno de los capítulos de su libro «América amiga se reúne en Praga». En el otoño de 1951, este escritor uruguayo, junto a los «invitados permanentes» Amado y Guillén, se encontró en Checoslovaquia con el novelista costarricense Carlos Luis Fallas, Enrique Gil Gilbert de Ecuador y José Luis Gonzáles de Puerto Rico. Esta situación extraordinaria está muy bien descrita así: «iTeníamos que venir a Checoslovaquia - me dijo pocas horas más tarde Nicolás Guillén, paseándonos por el maravilloso parque del castillo de Dolbrich [sic] - para encontrarnos toda América reunida... lo que no podemos hacer en nuestros países, increíble!» (Sosa, 286).

El castillo rococó de Dobrríš cerca de Praga jugó un papel muy importante en el estrechamiento de enlaces amistosos entre los intelectuales. En 1948 fue puesto bajo la administración de la Unión de Escritores Checoslovacos y sirvió como un lugar de descanso y relax. Se convirtió en un símbolo de la política cultural oficial del gobierno comunista y para muchos también en el símbolo de privilegios inapropriados (Ptáčník, 1993, 209). Allí se alojó durante más de dos años de exilio checoslovaco a la familia de Amado. Pablo Neruda, Nicolás Guillén, Raúl González Tuñón, Alfredo Varela o Jesualda Sosa, todos ellos tuvieron la oportunidad de conversar allí con otros huéspedes habituales: el ruso Ilya Ehrenburg, el turco Nazim Hikmet, la alemana Anna Seghers o los escritores checos Jan Drda, Vítězslav Nezval o Lumír Čivrný. Además, algunas de las obras de los personajes mencionados anteriormente demuestran que los contactos y amistades establecidos se mantuvieron hasta mucho después (Ehrenburg, 2014; Drda, 1955; Čivrný, 2000).

La vida cotidiana en Dobř́ís así como los contactos con los intelectuales de todo el mundo están descritos de manera interesantísima en las memorias de Zéllia Gattai Jardim de inverno (El Jardín de Invierno, 1988). "Los fines de semana no trabajaba nadie. Ni Jorge, ni los demás escritores que estaban escribiendo en el castillo. Ni Jan Drda - Presidente de la Unión de Escritores Checos -, empeñado por entonces en una novela. La monotonía de esos días se quebraba con la llegada de los visitantes: escritores con sus familias, artistas, gente del cine y hombres del gobierno. Uno de los que frecuentaba el castillo era el Primer Ministro, Antonin Zapotocky, que años más tarde sería Presidente de la República. Iba solo para descansar y practicaba de las alegres y dinámicas veladas en el gran salón, donde se cantaba, se conversaba, se hacían juegos de mímica y partidas de cartas» (Gattai, 1991, 29-30). 


\section{El discurso de los testimonios}

Se desprende de lo anterior que el objetivo de estos testimonios no era presentar a los compatriotas la imagen verdadera de la vida en los regímenes comunistas más allá de lo que pregonaba la propaganda masiva. Al contrario, los autores concebían sus obras como una obligación en la lucha contra el capitalismo. La creencia en el comunismo, el apego a la Unión Soviética y el esfuerzo por influir en la opinión pública a su favor son evidentes en estas obras. Como Jorge Amado dijo: «No basta amar, admirar, ser solidario con la URSS y las democracias populares. Es necesario que este amor, esta admiración, esta solidaridad sean activas y militantes (...) Es necesario ganar la batalla por la paz. Ganarla de cualquier manera» $(1953,347)$.

El discurso, fuertemente ideológico, se crea a través de dos ejes principales. El primero de ellos es el desarrollo general y el altruismo de los países comunistas. Al describir una sociedad utópica, el énfasis está en la justicia social, la libertad, la función protectora del Estado, el bienestar de las familias, los derechos de las mujeres, la posición excepcional de la juventud, el fuerte desarrollo de la cultura, la ciencia y la tecnología logrados en un tiempo extremamente corto. La gente en Europa Oriental era feliz, sana, positiva, y gracias a la educación gratuita y de calidad posesa otectivapego a la Unioía un conocimiento excepcional y, ante todo, eran amos de su destino, gracias, según ellos a Stalin, el hombre más grande de su época. Según Graciliano Ramos, un hombre de Europa Occidental o de América Latina no era capaz de comprender esta admiración incondicional por un político. «Sería ridículo si nos tributáramos una veneración por un político en América del Sur. En general, no tenemos ningún respeto por estos indivíduos» (Ramos, 1954, 54).

Los autores más leales, como Amado y Guillén, no podían hablar mejor sobre la diversidad de productos en las tiendas de Moscú. Si se hablaba negativamente sobre algo se le atribuía el carácter positivo de esta imperfección. Jesualdo Sosa explica su consternación inicial al ver que no había cinturones de seguridad en el avión a que los aviones de producción soviética eran tan seguros que no hacía falta tenerlos allí. El largo retraso lo razona con la explicación de que los soviéticos nunca expusieron una vida humana al peligro por intereses privados (Jesualdo, 1952).

Pablo Neruda manifestó su amor y devoción a la Unión Soviética en sus poemas, pero también en sus memorias. "Amé a primera vista la tierra soviética y comprendí que de ella salía no solo una lección moral para todos los rincones de la existencia humana, una equiparación de las posibilidades y un avance creciente en el hacer y en el repartir, sino que también interpreté que, desde aquel continente estepario, con tanta pureza natural, iba a producirse un gran vuelo. La 
humanidad entera sabe que allí se está elaborando la gigantesca verdad» (Neruda, $1975,213)$.

El segundo eje de estos textos es la percepción de la Unión Soviética y los países socialistas como defensores de la paz. Se niega el imperialismo ruso; se cree que cuando los rusos entraron en una guerra, siempre se debió a circunstancias extraordinarias. La idea de difundir la paz se ve como el resultado de la armonía social interna y la comprensión entre repúblicas y naciones. Al mismo tiempo se atacaban los puntos débiles del enemigo por medio de la simplificación y la exageración. Así, la misión de la Unión Soviética del mantenimiento de la paz se ponía en contraste con el capitalismo hambriento de guerras, que simbolizaba un nuevo tipo de fascismo.

La mayoría de las obras está influida por el realismo socialista y su valor artístico es cuestionable. Esto se puede aplicar ante todo en la obra de Amado El Mundo de la $\mathrm{Paz}$, de la que es evidente que fue «intentada al consumo inmediato»; el vocabulario del autor es más el vocabulario de las noticias de guerra. Si El Mundo de la Paz es la obra donde el autor describió lo que quería ver y no lo que vio con sus ojos propios, sus memorias Navegação de cabotagem (Navegación de cabotaje, 1992) reflejan en parte también lo que veía, pero no quería decir en aquel momento. Describen el camino desde la etapa de la creencia ciega hasta el conocimiento de la verdad dolorosa, el proceso, en cuyo principio la Unión Soviética se veía como «el paraíso en la tierra» y al final se convirtió en el enterramiento de la utopía, símbolo de la desilusión y la traición (Amado, 1992).

En El Mundo de la Paz las tiendas estaban llenas de productos y sus precios bajan sin cesar. La gente podía comprar todo lo que quería. Amado habla expresamente sobre la leche y la fruta que antes solo estaba disponible para niños y enfermos (Amado, 1953, 231-232). El libro de su esposa Zélia Gattai El Jardín de Invierno, publicado en 1988, muestra la vida en socialismo bajo una luz completamente diferente y más realista. Para una pareja acostumbrada a vivir en los trópicos brasileños fue muy difícil acostumbrarse a la imposibilidad de comprar fruta. Esto era aun más complicado porque la familia tenía dos niños pequeños: «Mi hijo, el pobrecito, que ni recordaba el gusto de la banana» (Gattai, 1991, 53). La escasez de productos no era el único problema. La familia de Amado también tuvo que enfrentarse con la ansiedad, el miedo y ante todo los procesos políticos, que se cobraron como víctima a un amigo cercano de la familia, Artur London. La larga estancia en el realismo socialista fue en realidad un período de transformación y desengaño y el principio de la decisión de Amado de abandonar el partido comunista, lo que ocurrió en 1955, tres años después de su regreso a Brasil. 


\section{Conclusión}

Los testimonios de viajes a Europa Oriental escritos por los intelectuales latinoamericanos presentan vínculos poco conocidos entre regiones remotas. Los autores de estos textos, miembros de los partidos comunistas locales, fueron representantes del discurso occidental y la manera de percibir el mundo comunista no se diferenciaba de la línea de sus colegas en Europa Occidental. El rasgo más característico de los testimonios de la época comprendida entre 1947-1956 es la lealtad absoluta a la Unión Soviética. El campo socialista es descrito como una sociedad utópica y no están ausentes ni declaraciones de amor. Por otra parte, los intelectales latinoamericanos se veían realmente asombrados tanto por la infraestructura cultural como la sabiduría de los ciudadanos medios, tomando en cuenta que muchos de sus compatriotas eran iletrados.

Por su contenido ideológico las obras de este período se parecen mucho a los textos de la época de entreguerras. Los autores de estos testimonios eran miembros de la organización prosoviética el Consejo Mundial de la Paz, viajaron con una invitación oficial y sus estancias eran cuidadosamente organizadas. Los textos fueron útiles para las necesidades políticas del momento y su valor literario es discutible. Por otro lado, se trata de testimonios notables de la época en la que la conexión con Europa Oriental contribuyó a la «internacionalización» de los artistas latinoamericanos. Este proceso se reflejó en el creciente número de traducciones, invitaciones a conferencias o a premios internacionales.

Una de las mayores contribuciones de los testimonios de viajes consiste en la descripción de los establecimientos de los circuitos de contacto entre los intelectuales latinoamericanos y los europeos. En definitiva, no deja de resultar paradójico que el primer encuentro de los destacados personajes fuera realizado en Europa Oriental. En América Latina, donde los intelectuales izquierdistas en muchos casos eran objeto de persecuciones, no había espacio para una reunión de este tipo.

\section{Bibliografía}

Alburquerque, G., La trinchera letrada. Intelectuales latinoamericanos y guerra fría, Santiago de Chile 2011.

Amado, J., O Mundo da Paz, Rio de Janeiro 1953.

Amado, J., Navegación de cabotaje, Buenos Aires 1992.

Bárta, M., Právo azylu. Vznik politické emigrace v Československu po roce 1948, Pamět’ a dějiny 5/1, 2011, pp. 15-22. 
Bartosek, K., Les aveux des archives, Prague-Paris-Prague, 1948-1968, París 1996.

Bergstein, J., Repensando el socialismo: Enfoques a partir de un caso puntual, Checoslovaquia, Buenos Aires 1996.

Camp, R. A., Los intelectuales y el estado en el México del siglo XX, México 1988.

Čivrný, L., Co se vejde do života, Praha 2000.

Dalton, R., Taberna y otros lugares, La Habana 1969.

Delgado, Á., Todo tiempo pasado fue peor, Bogotá 2007.

Drda, J., Horká půda, Praha 1955.

Ehrenburg, I., Gente, años, vida (Memorias 1891-1967), Barcelona 2014.

Fayet, J.-F., La Société pour les échanges culturels entre l'URSS et l'étranger (VOKS), Relations Internationales 115, 2003, pp. 416-419.

Franco, J., The Decline and Fall of the Lettered City. Latin America in the Cold War, Harvard 2002.

Galeano, E., Los blues de Siberia y las brumas de Praga, en: Nosotros decimos No, Crónicas, 1963-1988, Buenos Aires 2011, pp. 42-45.

Galvan, V., Zourek, M., Artkino Pictures Argentina: a Window to the Communist Europe in Buenos Aires Screens (1954-1970), Politické vedy 19/4, 2016, pp. 36-51.

Galvan, V., The impact of the Soviet Repatriation Campaign on the Eastern European Émigré Community in Argentina (1955-1963), Littera Scripta 10/1, 2017, pp. 22-34.

García Márquez, G., De viaje por Europa del Este, Buenos Aires 2015.

Gattai, Z., Jardim de Inverno, Buenos Aires 1991.

Gilman, C., Entre la pluma y el fusil. Debates y dilemas del escritor revolucionario en América Latina, Buenos Aires 2003.

González Tuñón, R., Todos los hombres del mundo son hermanos, Buenos Aires 1954.

Gravina, A., Crónica de un viaje a la URSS y Checoslovaquia, Montevideo 1955.

Guillén, N., En la República Popular de Bulgaria, Última Hora, 29. 5. 1951.

Guillén, N., En Hungría el trabajo es como un juego y la vida una canción, Última Hora, 5. 6. 1951.

Guillén, N., Quince días en la República Popular Rumana, Hoy, 16., 23., 30. 12. 1951.

Guillén, N., Páginas vueltas: Memorias, México 1982.

Huerta, E., Praga mi novia, México en la Cultura, Suplemento Dominical de Novedades, 384, 29 julio, 1956, p. 3.

Iggers, G. G., Wang, Q. E., Mukherjee, S., A Global History of Modern Historiography, Harlow 2008. 
Joseph, G. M., Los que sabemos y lo que deberíamos saber: la nueva relevancia de América Latina en los estudios sobre la guerra fría, en: Espejos de la guerra fría: México, América Central y el Caribe (coord. Spenser, D.), México 2004, pp. 67-92.

Malbec, E. F., Yo los ví así: Alemania, Suecia, Finlandia, Polonia, Hungría, Checoslovaquia, Turquía, Buenos Aires 1963.

Middell, M., Hadler, F., Challenges to the History of Historiography in an Age of Globalization, en: The Many Faces of Clio. Cross-cultural Approaches to Historiography, Essays in Honor of Georg G. Iggers (eds. Wang, Q. E., Fillafer, F. L.), New York, Oxford, 2007, pp. 293-306.

Monsiváis, C., De los intelectuales en América Latina, América Latina Hoy 47, 2007, pp. 15-38.

Mudrovcic, M. E., Mundo Nuevo. Cultura y Guerra Fría en la década del 60, Rosario 1997.

Nálevka, V., Španělé v poválečném Československu, en: Dvacáté století. Ročenka Semináře nejnovějších dějin Ústavu světových dějin Filozofické fakulty Univerzity Karlovy v Praze, 2005, pp. 77-95.

Neruda, P., Confieso que he vivido, Barcelona 1975.

Neruda, P., Las uvas y el viento, Santiago de Chile 2003.

Osgood K., Total Cold War: Eisenhower's Secret Propaganda Battle at Home and Abroad, Lawrence 2006.

Pecaut, D., Os intelectuais e a política no Brasil. Entre o povo e a nacão, São Paulo 1990.

Pedemonte, R., La diplomacia cultural soviética en Chile (1964-1973), Bicentenario, Revista de Historia de Chile y de América 9/1, 2010, pp. 57-100.

Pedemonte, R., Pablo Neruda, su tiempo y el «sentido de la historia»: postura ideológica y creación poética durante la Guerra Fría, Ayer 98/2, 2015, pp. 159-185.

Ptáčník, K., Život, spisovatelé a já, Praha 1993.

Ramos, G., Viagem (Checoslováquia - U.R.S.S.), Rio de Janeiro 1954.

Riza, B., Quirk, C., Relaciones culturales entre la Unión Soviética y América Latina, en: La Unión Soviética y la América Latina (eds. Oswald, G., Strover, A.), México 1972, pp. 39-51.

Rojas, R., Tumbas sin sosiego. Revolución, disidencia y exilio del intelectual cubano, Barcelona 2006.

Rupprecht, T., Soviet Internacionalism after Stalin. Interaction and Exchange between the URSS and Latin America during the Cold War, Cambridge 2015.

Santana, J. G., Nicolás Guillén, juglar americano, un poeta por la revolución, La Habana 1989. 
Schidlowsky, D., Neruda y su tiempo. Las furias y las penas, vol. 2, Santiago de Chile 2008.

Sigal, S., Intelectuales y poder en la década del sesenta, Buenos Aires 1991.

Sirinelli, J.-F., Ory, P., Los intelectuales en Francia. Del caso Dreyfus a nuestros días, Valencia 2007.

Sosa, J., Mi Viaje a la URSS, Montevideo 1952.

Suárez, L., Otro Mundo. Viaje por Checoslovaquia, Rumania y Polonia, México 1954.

Terán, O., Nuestros años sesentas: la formación de la nueva izquierda intelectual en la Argentina 1956-1966, Buenos Aires 1991.

Torres, J., Viaje a Rusia: y otros países socialistas, Buenos Aires 1962.

Uricoechea, F., Intelectuales y desarrollo en América Latina, Buenos Aires 1969.

Varela, A., Un periodista argentino en la Unión Soviética, Buenos Aires 1950.

Zourek, M., Checoslovaquia y el Cono Sur 1945-1989. Relaciones políticas, económicas y culturales durante la Guerra Fría, Praga 2014. 
Michal Zourek

\section{Potovanja latinskoameriških intelektualcev v Vzhodno Evropo 1947-1956: organizacija, stiki in razmišljanja}

Ključne besede: intelektualci, Latinska Amerika, kulturne povezave, hladna vojna, komunizem, Svetovni mirovni svet, Jorge Amado, Pablo Neruda, Nicolás Guillén

Študija proučuje potovanja latinskoameriških intelektualcev v Vzhodno Evropo, da bi osvetlila nekatere do nedavnega manj poznane vezi med tema oddaljenima regijama. Gre za časovno obdobje med letoma 1947 in 1956, ki ga je zaznamovalo veliko navdušenje levičarskih intelektualcev nad Sovjetsko zvezo in državami socialističnega bloka. Avtor najprej predstavi individualna pričevanja in jih umesti v točen kontekst glede na vlogo latinskoameriških intelektualcev v komunistični propagandi in njihove odnose $\mathrm{z}$ mednarodnimi organizacijami. Posebno pozornost posveti organizaciji potovanj in njihovemu prispevku $\mathrm{k}$ vzpostavljanju stikov $\mathrm{z}$ vzhodnoevropskimi intelektualci. Tretji del študije predstavlja analiza diskurza teh besedil. Ta so služila trenutnim političnim potrebam, vprašljiva pa je tudi njihova literarna vrednost. Po drugi strani pa gre za pomembna pričevanja o obdobju, v katerem je povezava z Vzhodno Evropo prispevala $\mathrm{k}$ internacionalizaciji latinskoameriških umetnikov. Ta proces se je odrazil v naraščajočem številu prevodov, povabilih na konference in mednarodnih nagradah. Enega največjih prispevkov pričevanj o potovanjih predstavlja opis navezovanja stikov med latinskoameriškimi in evropskimi intelektualci. Paradoksalno se je prvo srečanje pomembnih osebnosti zgodilo v Vzhodni Evropi. V Latinski Ameriki, kjer so bili levičarski intelektualci mnogokrat preganjani, srečanja namreč niso bila mogoča. 


\section{Michal Zourek}

\section{Journeys of Latin American intellectuals to Eastern Europe in 1947-1956: organization, contacts and reflection}

Keywords: intellectuals, Latin America, cultural relations, Cold War, communism, World Peace Council, Jorge Amado, Pablo Neruda, Nicolás Guillén

This study analyses the journeys of Latin American intellectuals to Eastern Europe in order to clarify hitherto unknown links with the region. The focal period is the decade of 1947-1956, which was characterised by the great enthusiasm leftist intellectuals felt towards the Soviet Union and the countries of the socialist block. The first part of the study presents individual written testimonies. These are put into perspective with regard to the role Latin American intellectuals played within the framework of communist propaganda and their relations with international organizations. Special attention is paid to the organization of these journeys, and to the way they contributed to the development of contacts with intellectuals in Eastern Europe. The third part of the study provides an analysis of the discourse of such texts. On the one hand, it is argued that the texts served the political needs of the time, and that their artistic value is disputable. On the other hand, the texts are remarkable testimonies of the period, one in which the connection with Eastern Europe contributed significantly to the "internationalisation" of Latin American artists. This was reflected in the increasing number of translated works of the authors, invitations to various conferences, or international prizes awarded to Latin American artists. One of the major benefits of the testimonies is the fact that they describe the contacts established between Latin American and European intellectuals. It is rather paradoxical that the first reunion of prominent Latin American figures took place in Eastern Europe. In Latin America, where leftist intellectuals were frequently subjected to persecution, such meetings would not have been possible. 